\title{
New Directions in Macroeconomics
}

\author{
Editors \\ Received: 22.12.2019 Accepted: 02.05.2020 Published: 30.04.2020 \\ doi: 10.33818/ier.747603
}

\begin{abstract}
The glaring failure of modern macroeconomics to predict the Global Financial Crisis, and to provide remedies for the Great Recession which followed, has led to renewed interest in alternative approaches to Macroeconomics. There is huge amount of ongoing work aimed at creating a Macroeconomics for the $21^{\text {st }}$ Century. The task is of the highest priority, as failures of economic theory have led to misery for millions. Wrong measures of GDP, and cost-benefit calculation which fail to account for environmental costs, and prioritize private profits over social welfare, have created a climate catastrophe which threatens to destroy the planet. In accordance with the importance of this task, we are expanding the scope of this journal, to cover all new approaches to economics, which fall outside of the boxes of conventional macro, micro, and econometrics of the $20^{\text {th }}$ Century. This article outlines seven broad categories of research directions, and four different methodological principles which fall outside the boundaries of the conventional approach, and offer promise for building a Macroeconomics for the $21^{\text {st }}$ Century. We hope to invite contributions in these areas for future issues.
\end{abstract}

Key words: Political Economy, Complexity Economics, Ecological Economics, PostKeynesian Economics, Islamic Economics

JEL Classifications: B41, B50

\section{HISTORICAL CONTEXT OF CURRENT CRISIS}

There is widespread awareness of the catastrophic failures of modern macroeconomic theories, especially in the wake of the Global Financial Crisis of 2007. For instance, Krugman (2009) wrote that the profession as a whole went astray because they mistook the beauty of mathematics for truth". Paul Romer (2016), recent Nobel Laureate, wrote "The Trouble with Macroeconomics" which contains a devastating critique of modern macroeconomics. In particular, Romer writes that modern macro got started when Lucas and Sargent wrote that predictions based on Keynesian economics "were wildly incorrect, and that the doctrine on which they were based is fundamentally flawed". But after three decades of research, during which the profession has gone backwards, losing hard-won insights into the nature of the economy, exactly the same criticism can be leveled at modern macro theories - they give wildly incorrect predictions and are based on fundamentally flawed doctrines, beyond the possibility of repair. Economists were unable to forecast the Global Financial Crisis, and were unable to take policy actions to prevent the Great Recession which followed. This created levels of homelessness and hunger not seen in the USA since World War 2. The general public noticed this failure. The Queen of England went to London School of Economics to ask "why no one could see it coming". In an unprecedented move, the US Congress appointed Subcommittee for Investigations and Oversight to hold hearings on "Building a Science of Economics for the Real World"; see Solow (2010). The committee was charged with investigating the failure of economics profession to predict the crisis. Even worse, "generally accepted economic models inclined the Nation's policy makers to dismiss the notion that a crisis was possible". Not only 
did economists fail to predict the crisis, many economists and practitioners who issued warnings were silenced and dismissed, because the possibility of a crisis did not exist in macroeconomic models then in use. Sadly, these models continue to be the mainstream macroeconomic models being studied and taught all over the world today, even though better alternatives are available. We will use the general label " $21^{\text {st }}$ Century Economics" to refer to these alternatives, and describe them in this introductory article.

In a blog post on "What Went Wrong", Paul Romer (2020) describes how economic theorists became central to policy making in the USA in the 1970's. He argues that this experiment of turning over policy to economists has been a disastrous failure, and economic theory-based policies have resulted in low growth and lowered life expectancies. In this brief outline and survey, we will discuss the many dimensions where radical changes are required in methodology and approach to fundamental economic questions. This is merely and outline and a sketch, not a detailed argument. Our goal is to encourage submissions to this journal in the areas discussed, so as to create the basis for a change towards " $21^{\text {st }}$ Century Economics". In future issues, we will adopt this as a subtitle, to signal a change in editorial policies and subject matter for this journal.

\section{BROAD CATEGORIES OF RESPONSES}

The response of mainstream macroeconomists to this crisis has been disappointing; see for example Antara Haldar (2018) "Economics: The Discipline that refuses to change". The failure of classical economics in the Great Depression of 1929 led Keynes to the create the field of macroeconomics, which was revolutionary many different ways. Unfortunately, as Romer remarks, the profession went backwards, losing hard-won insights. All of the revolutionary Keynesian insights (discussed in greater detail below) have since been rejected by the orthodoxy. Similarly, there has been little or no response to the demonstrated failure of macroeconomic models following the Global Financial Crisis. In Zaman (2020, this issue) "Models and Reality", I have explained how current economic methodology prevents economists from creating better models in response to empirical failure. Instead of re-thinking economics, mainstream economists have closed ranks along a defense of the orthodoxy. A consensus has emerged that no major change is required. For example, Krugman attributes the failure of macro to three factors: (i) a "Black Swan event" of such low probability that it could not have been foreseen by anyone, (ii) prolonged maintenance of low interest rates by the Fed (flawed monetary policy), and (iii) emergence of a huge shadow banking sector not taken into account by macroeconomists monitoring the economy. The point of this deeply flawed defense is to argue that there is no need to change the fundamental frameworks for macroeconomics. As a result of this failure to reform theory, the same macro models which failed catastrophically in the Global Financial Crisis continue to be used all over the world. DSGE-based macro models with no role for money and banking, and GARCH models forecasts of volatility, are still in use at Central Banks throughout the world, because no viable alternative has emerged.

While mainstream economists have failed to respond, there has been substantial recognition of the challenge, and many important heterodox responses to the crisis in macroeconomics created by the Global Financial Crisis. Some of the main lines of response have been as follows.

\subsection{Post-Keynesian Economics}

By now, this is an advanced and sophisticated school of thought which builds upon multiple revolutionary insights of Keynes, rejected by mainstream macroeconomics. We discuss three 
of these briefly below. A fourth insight of great importance was the understanding that macro phenomena did not emerge by aggregating the micro phenomena - the system is not just the sum of its parts. This is now called "complexity economics" and is discussed in a separate subsection.

Money matters, in the short run and in the long run. It is surprising that this needs to be said, since it seems entirely obvious to everyone except economists, who teach that money is neutral. Real Business Cycle Models of the economy currently in use for monetary policy have no direct role for money and no financial sector. As somebody quipped, this is like trying to figure out how birds fly, without taking into account their wings. Romer (2016) expresses his exasperation at major league macroeconomists who write that money plays no significant role in the economy, and provides strong empirical evidence for the importance of money by study monetary policy of Volcker. Arestis and Sawyer (2006) provide a comprehensive review in their Handbook of Alternative Monetary Economics. An example of how these post-Keynesian theories affect orthodox views of growth, interest, and money is provided by Dutt and Amadeo (1993).

Radical Uncertainty: Keynes argued that the future is inherently uncertain and unpredictable. Unfortunately, some erroneous technical arguments were used to show that rational decision making could be based on probability estimates of future events, denying the possibility of radical uncertainty. John Kay (2019) writes the "To acknowledge the role of radical uncertainty is to knock away the foundations of finance theory and much modern macroeconomics." For example, rational expectations is at the heart of modern theories of finance and macroeconomics, and makes events like the Global Financial Crisis impossible. A landmark book on Radical Uncertainty by Kay and King (2020) argues that rejection of Keynesian uncertainty was a central reason for the blindness of economists, and economic theories, to the possibility of the Global Financial Crisis. These theories continue to dominate, while recognition of radical uncertainty is a necessary preliminary to the rebuilding of a more relevant economic theory. For a deeper discussion of the technical arguments which led to the rejection of uncertainty, see Zaman (2019).

Demand Driven Output: Keynes opens his famous book by rejecting Say's Law, which states that supply creates its own demand. In contrast, he argued for the principle of effective demand, that demand matters in the long as well as the short run. Unfortunately, modern macroeconomics has re-instated Say's Law, and ruled out the possibility of long-run unemployment of labor or other resources. The success of the counter-revolution of Chicago style free market economics, launched against the Keynesian revolution, has left economists blind to the mysteries of the labor market. For example, Borjas (2016) agrees that 'marginal productivity theory bears little relation to the way that employers actually make hiring decisions'. He writes that "We do not yet fully understand why the recent evidence differs so sharply from the evidence presented in the earlier literature, and why the implications of our simple-and sensible supply and demand framework seem to be so soundly rejected by the data." Similarly a recent conference on the mystery of rising productivity together with stagnant wages was the subject of a recent conference, where top economists admitted to being bewildered by this phenomenon. See Denning (2013) for a collection of quotes displaying the confusion and frustration of economics, and an explanation of the problem based on the evolving structure of corporate finance. Post-Keynesian theories build on Keynesian ideas to provide deep insights into the functioning of the labor market. Providing good jobs to everyone is arguably the most important function of an economic system, and one which modern economies fail miserably to 
do. To create full employment, it is essential to fix economic theory, which solves the problem by pretending it does not exist.

\subsection{Modern Monetary Theory}

Since the time of Keynes, major changes have taken place in the global financial system. Against wishes of Keynes, Bretton-Woods created a dollar centered system based on notional exchangeability of dollars for gold. The Nixon Shock in 1971 removed the gold backing from dollars, leading to the modern world of floating exchange rates. Dramatic changes in the monetary exchange systems and financial institution play no role in orthodox modern macroeconomics, since money and finance are not (supposedly) part of the real economy. Taking the nature of modern money and the financial institutions into serious considerations leads to many important insights which lie at the core of MMT. Three major innovations lie at the foundations of this theory. These are summarized below:

Endogenous Money: MMT reflects an institutional perspective on the creation of money. When Central Banks set discount rates, they lose control of the quantity of money, which must be issued in amounts required to equilibriate the demand/supply of money at the policy rate. Private creation of money depends on bank-lending, which in turn depends on the investment climate. Bank credit depends on expectations, sound collaterals, and also a keeping-up-withthe-Joneses effect - if everyone is lending, banks cannot afford to stay out Theories of endogenous money underlie Minsky's Financial Fragility Hypothesis, which suggests that the money creation process is inherently destabilizing because private credit is expanded at the top of the business cycle and contracted at the bottom, exactly the opposite of what is required for good economic management.

Functional Finance: Orthodox macro enforces a budget constraint on the government, embodied in the so-called "Ricardian Equivalence". A key proposition of MMT is that the government does not face a budget constraint. The "deficit" number is meaningless; both taxation and spending serve different economic purposes, and should be used as required by economic considerations. Taxation does not provide revenue for the government, but rather serves to dampen aggregate demand. Government spending is required to generate profits for firms, and savings for households by injecting money into the economy. The government can and should achieve full employment using appropriate fiscal policy measures. However, this spending must be carefully targeted and suitably constrained, in order to avoid inflation.

Intersectoral Flow of Funds: MMT incorporates Kalecki's approach towards inter-sectoral balances, which provide refinement of Keynesian ideas. Fiscal policy should take careful account of the different sectors of the economy. Money creation may pump money into the wrong sectors, leading to inflation long before it reaches the sectors with excess capacity, where it could reduce unemployment. Thus a carefully crafted job guarantee program, which does not compete with private jobs, is at the core of policy recommendations generated by an MMT perspective. For more details on how these ideas could be implemented, see Zaman (Jan 7, 2020).

\subsection{Political Economy}

Once we recognize the importance of history and institutions, it becomes clear that economic problems cannot be separated from politics and society. The interplay of class interests, and their relative power, is of essential importance in understanding political and economic 
structures of society. Current commitment to methodological individualism has blinded economists to these aspects, and left them unable to explain burning issues like the rapid rise of income inequality in the wake of financial de-regulation. There are many different perspectives from which the inter-relationships between politics and economics can be analyzed.

Marxist Perspective: Although the Marxian prediction of the demise of Capitalism has proven wrong, the methodology and tools he developed yield insights not available within the orthodoxy. Moore (2015) shows that dynamics of capitalism require ever increasing exploitation of all available resources. However, with the imminent exhaustion of planetary resources on a global scale, capitalism. A key Marxian insight is that exploitation is enabled by an ideology which creates an appearance of fairness, necessity and optimality of the capitalist economic system. For an illustration of how modern economic theory fulfills this role, see Zaman (Apr 1 2018, ET1\%: Blindfolds Created by Economic Theory). Unlike orthodox macroeconomics, Marxist theory is well suited to understanding the global nature of capitalism; for key references, see Burnham (2001). Marxist analysis is also very helpful in understanding increasing inequality and exploitation, which is responsible for the inherent instability, and repeated crises, of the capitalist economy. Harvey (2017) is a useful introduction to contemporary understanding of Marxist theory, together with a critique of orthodoxy.

The Great Transformation: Polanyi's famous book (see Zaman, Aug 28, 2013) for a summary) provides a deep analysis of the transformation in England from a traditional society to a market society. As he shows, emergence of the market mechanism created conforming changes in politics, society, and our attitudes towards the planet and people. Polanyi shows how social transformations work through collective efforts of classes, which are embodied in the form of institutions. However, he does not take classes and institutions as exogenously given. Rather, he shows how social transformation can create or destroy classes, and also institutions, in accordance with shifting balance of powers created by a complex of forces which act from within or without. Three major methodological principles used by Polanyi for the study of social change are articulated in Zaman (2016). All three run counter to received wisdom in contemporary economic methodology, and therefore furnish the basis for an alternative 21 st Century approach to economics.

The New Political Economy: Many have come to realize the impossibility of understanding economic crises of the past century without taking into account the political and historical context, as well as a deep analysis of the institutional structures. See for example "There is no economics without politics" by Admati (2019). This has led to the emergence of a new eclectic approach to the study of close connections between politics and the economy. The recently established Department of Political Economy at Kings College London provides as raison d'etre: "In a world characterized by financial uncertainty, ecological insecurity and value conflict, the links between political and economic processes are ever more apparent and the need for a multifaceted appreciation of how they operate, has never been greater." As an illustrative example, Lemann (2019) provides an account of how economic theories, combined with political power, reshaped institutions and policies to dramatically change the social, political, and economic landscape over the past century. Combining political, institutional, and historical methods leads to deep insights into the workings of our economic system not available within the orthodoxy. A comprehensive and thorough book-length is provided in a draft textbook on Political Economy by Daron Acemoglu (2020). 


\subsection{Evolution of Global Finance}

The Hegelian anti-thesis of the orthodox economic position that money is neutral, is the idea that "money is everything". Economics is just the analysis of monetary flows, both within a society, and globally. Karl Marx describes the change in perspective via the formulae C-M-C' versus M-C-M'. In the first paradigm, commodities $\mathrm{C}$ are sold to get money $\mathrm{M}$, in order to buy another set of commodities C'. This picture of a barter economy, in which money just facilitates exchange, is at the heart of modern economics; this is why money does not matter. However, in a capitalist economy, $\mathrm{M}$ (oney) is used to produce commodities $\mathrm{C}$, and these are sold for more money M'. Money is the goal of production and sales, not an instrument for exchange of commodities. An economy where the drive for profits is the main motivation for productions and purchases, requires an entirely different analysis.

In his classic work on "The Long Twentieth Century: Money, Power, and the Origins of Our Times", Giovanni (1994) describes how the accumulation of capital (wealth, money) has been the central driver of history over the past several centuries. Giovanni provides a wealth of historical details and a global context to support this thesis, based on a world-systems perspective. Many other authors, writing from money different perspectives, have documented how "money makes the world go around".

In particular, Minsky's (1986) analyses of this phenomena are of special importance from the economic point of view. Minsky studies the evolution of finance (and financial capitalism) over the 20th Century. The creation of Central Banking led to a wild expansion of credit in the roaring 20's, and the resulting collapse of the Great Depression. This resulted in strong regulations on banking, as well as the emergence of a welfare state. Big government for countercyclical budgets and the Central Bank to regulate finance led to a stable capitalist system which worked for decades. As per financial fragility hypothesis of Minsky, stability generated large amounts of savings, and creation of competitive pressure to earn high returns by taking larger risks. Large amounts of money in pension funds and hedge funds created "Money Manager Capitalism", where managers of massive amounts money have high incentives to take risks, because their interests as managers are not aligned with those of the owners. Managers of capital were able to change rules towards increasing de-regulation, and to privatize gains, while distributing losses to the general public. This increasing fragility has led to crises of increasing severity, culminating with the Global Financial Crisis.

Minsky's theories are in radical conflict with orthodoxy in modern macroeconomics in many dimensions. In particular, Minsky (1986) argues that manager finance is inherently unstable. A good growth equilibrium creates increasing incentives for risk-taking and leads routinely to crisis. This is the opposite of the orthodox view that economies tend towards stable equilibria, and far better aligned with the data on hundreds of financial crises in the past few decades.

\subsection{Ecological Economics}

Eurocentric history portrays the West as advanced, rational, scientific, and democratic, while the East is superstitious, unscientific, autocratic, and backwards. World Systems theory was developed as an antidote to portray all human beings, nations, and cultures, as joint participants in weaving the rich fabric of human history. Ecological economics goes further to take the entire humanity as one element of the biosphere and geosphere of our planet. All of the biological species have their "economics" where they consume and produce, directly or indirectly affecting other species. All of these economies are closely interlinked. Viewed in this light, the 
environment crisis is easily seen as being due to human beings' predatory consumption of vast proportions of the biosphere and the geosphere, without any compensatory productive replenishment.

Conventional economics assumes that ever-increasing GDP is desirable, possible, and that everyone benefits, because it does not take into account costs inflicted on the biosphere and geosphere, which will ultimately be borne by human beings as well. Ecological economics takes a broader perspective and recognizes that there are more things that contribute to human wellbeing than just the amount of stuff, such as health and education (human capital), friends and family (social capital) and the contribution of the earth and its biological and physical systems (natural capital). Its goal is to develop a deeper scientific understanding of the complex linkages between human and natural systems, and to use that understanding to develop effective policies that will lead to a world which is ecologically sustainable, has a fair distribution of resources (both between groups and generations of humans and between humans and other species) The related field of Green Economics is in general a more politically applied form of the subject.

Doughnut economics is a visual framework for sustainable development - shaped like a doughnut - combining the concept of planetary boundaries with the complementary concept of social boundaries. The framework was proposed to regard the performance of an economy by the extent to which the needs of people are met without overshooting Earth's ecological ceiling. The name derives from the shape of the diagram, i.e. a disc with a hole in the middle. The centre hole of the model depicts the proportion of people that lack access to life's essentials (healthcare, education, equity and so on) while the crust represents the ecological ceilings (planetary boundaries) that life depends on and must not be overshot. Consequently, an economy is considered prosperous when all twelve social foundations are met without overshooting any of the nine ecological ceilings. This situation is represented by the area between the two rings, namely the safe and just space for humanity. The diagram was developed by Oxford economist Kate Raworth in the Oxfam paper A Safe and Just Space for Humanity and elaborated upon in her book Doughnut Economics: Seven Ways to Think Like a 21st-Century Economist.

\subsection{Complexity Economics}

Classical Physics, the model for modern economics, was based on the ideas of stability and permanence of astronomical orbits; see Mirowski (1992). Deeper examination of astrophysics led to the replacement of this view by big bang which gave birth to the universe, and increasing entropy, which will lead to its heat death. "Equilibrium" just appears as a temporary and local phenomenon in an evolving and chaotic universe.

Complexity economics takes non-equilibrium seriously. Constantly evolving systems may never be in equilibrium and may even lack a tendency towards equilibrium. The mode of analysis required for such systems cannot be based on the kind of mathematic currently dominant in the economics profession. Complex systems theory was pioneered in the 1980s and 1990s by a small team at the Santa Fe Institute led by W. Brian Arthur. Some of the key elements of this approach to economics can be described as follows:

1) Computational Aspects: It is essential to understand how closely our analytical methods correlate with our computational abilities. Just as tensor calculus enabled the discovery of relativity by Einstein, the computer power today enables us to explore consequences of behavioral assumptions far beyond the capabilities of mathematical formulae. Even the mechanics of human motion cannot be captured in formulae, but can 
be expressed and represented as a linked network on computers. Similarly, computers today allow us to capture ana analyze dynamics of extremely complex systems.

2) Complex Features: Brian Arthur et al. (1997) describe several features of complex systems which create models of types not easily accessible by conventional analytical tools and techniques. These include

a) No global controller - Controls are provided by mechanisms of competition and coordination between agents. Economic actions are mediated by legal institutions, assigned roles, and shifting associations. No global entity controls interactions.

b) Cross-cutting hierarchical organization-The economy has many levels of organization and interaction. Units at any given level behaviors, actions, strategies, products typically serve as "building blocks" for constructing units at the next higher level. The overall organization is more than hierarchical, with many sorts of tangling interactions (associations, channels of communication) across levels.

c) Ongoing adaptation-Behaviors, actions, strategies, and products are revised frequently as the individual agents accumulate experience.

d) Out-of-equilibrium dynamics - Because new niches, new potentials, new possibilities, are continually created, the economy functions without attaining any optimum or global equilibrium. Improvements occur regularly.

3) Interactions between Groups and Individuals: Individual behaviors create group responses, but individuals also respond to group dynamics. There is two-way interaction between groups and individuals. In response to a price change, the individual response of a firm is conditions on its assumptions about the group response. In turn the group response aggregates individual responses, creating complexity and emergent behaviors. Radical uncertainty and black swans enter the picture because we cannot anticipate how others model the system and make decisions, but these decisions affect our decisions and outcomes.

Some of the successful applications of complexity include the economic complexity index (ECI) introduced by Hausmann et al. (2011), which is highly predictive of future GDP per capita growth. Arthur (2018) describes some of the striking successes of complexity economics as follows: "the increasing-returns work done in the 1980 s ... shows how network effects lead to lock-in and dominance of one or a few players. This can't be done by equilibrium economics - it's not an equilibrium phenomenon. Now all of Silicon Valley accepts this theory and operates by it. Another major contribution is to asset pricing, where all rational market theories were proven failures in the GFC 2007. Complexity doesn't assume there is an equilibrium and set out to find it. It assumes investors don't know what the market is doing and must learn for themselves what works - which itself changes the market. The results show phenomena seen in real markets: technical trading, correlations among price and volume, and periods of high volatility followed by low volatility (GARCH behavior). Thus, unlike rational expectations, complexity theory explains real world financial phenomena." 


\subsection{Islamic Economics}

Islam provides a radically different approach to Economic affairs. Conventional economics is based on Jeremy Bentham's views that the purpose of life is to maximize pleasure. Accordingly, rational behavior is geared to achieve this goal. As opposed to this, Islam teaches us that human beings are born with infinite potential - each life is equal in potential to the entire humanity. The goal of our lives is to develop this potential that all of us are born with. Consumption of goods, and worldly pleasures distract us from the achievement of this purpose. According, Islam teaches us moderation in pursuit of worldly pleasures, combined with methods for spiritual advancement and progress. See Zaman (2019) for more details.

Viewing all of the creation as the family of God, Islamic views are strongly aligned with ecological economics, which views the biosphere as an organic whole. The emphasis on simple lives, where we are encouraged to live comfortably but to avoid waste, is in line with the idea that de-growth is essential for sustainable development. A key to this path is distinguishing between needs and wants, and emphasizing the fulfillment of needs, while discouraging the fulfillment of idle desires. To see how this resolved the fundamental problem of scarcity, and replaces it with a different central problem, ensuring basic needs for all, see Zaman (2010).

The above seven categories are just a representative sample of major trends in out-of-the-box thinking required to launch a revolution in macroeconomic theory. For our future issues, we would encourage readers to provide us with submissions in any of these areas. In addition to research, we would also be happy to publish, reviews, pedagogical articles, discussions, and debates on controversies created by the application of these new ways of thinking to the solution of classical economic problems. In the next section, we identify some specific directions in which work is likely to provide fruitful results, and low hanging fruit are available from investments in research.

\section{FOUR METHODOLOGICAL PRINCIPLES}

Zaman (2020, this issue) explains how current economic methodology is seriously flawed, and leads to creation of models which are divorced from reality. In future issues of IER: 21st Century Economics, we would like to see contributions aimed at developing new methodologies, based on integrating historical context, political, social, and institutional frameworks, into the study of economics. In this connection, some elements of a unifying methodology can be obtained from Polanyi's (1945) study of processes of social change. Zaman (2016) identifies three elements of Polanyi's methodology which run counter to widely accepted principles of current orthodox economic methodology. In addition, it is of vital importance to take normative values into explicit consideration, in arriving at policy recommendations. This leads us to four recommendations for new methodological principles for 21 st century economics.

\subsection{Entanglement of History with Theory}

In Zaman (March 22, 2018), I have discussed the Methodenstreit, or Battle of Methodologies, which took place in the late 19th Century. In this battle, the natural methodology for economics, which is historical and qualitative, lost out to the newly developed scientific and quantitative methodology. While the scientific method is well suited to the study of inanimate objects subject to laws, its application to human beings and societies led to a loss of understanding. Modern economics treats human behavior as robotic, subject to mathematical laws. Many 
economists have complained of the increasing use of mathematics, at the cost of real understanding. For example, Krugman (2009) wrote that "the economics profession went astray because economists, as a group, mistook beauty, clad in impressive-looking mathematics, for truth". Similarly, Romer (2015) talks about "Mathiness", where complex math is used to hide irrelevance, and lack of connections to reality.

One of the major effects of the Methodenstreit is documented by Hodgson (2002) in his book entitled How Economics Forgot History. Because economic theories are developed as universal laws, valid across space and time, students never learn about the historical context. In fact, we cannot understand Keynesian economics without understanding the Great Depression which led to its birth. The economic theories of hunter-gatherer societies are very different from that of feudal societies. The evolution of economic theories over time corresponds to the evolution of economic systems over time. Removing historical context leads to substantial loss of understanding. Of even greater interest is the reverse interaction - how economic theories shape history. The mistaken theory of the Phillips Curve, and the later update to the Expectation Augmented Phillips Curve, has guided monetary policy for several decades. As Mitchell et al. (2019) argue, this has led to disastrously poor economic policies, which have created vast amount of unemployment, ruining millions of lives. Applebaum (2019) shows the rise in influence of economists, and the disastrous effects of implementing policies based on current economic theories.

Incorporating and teaching major economic events of the twentieth century in their historical aspects would substantially enrich a conventional economics education based entirely on mathematics and theory. Many books can be of substantial value in this effort. For teaching about development, there is currently no alternative to L. S. Stavrianos: Global Rift The Third World Comes of Age. Understanding how the agenda of neoclassical economics has shaped global economic policies is covered by Naomi Klein's The Shock Doctrine: The Rise of Disaster Capitalism. An excellent book which shows how to merge history with economics of trade is Power and Plenty: Trade, War, and the World Economy in the Second Millennium by Ronald Findlay \& Kevin H. O'Rourke. The authors write that: "This book was written in the belief that you cannot make sense of today's world economy, or indeed of the world more generally, without understanding the history that produced it." Anyone who studies history will realize the that this is an essential component missing from modern economic theory.

\subsection{Inter and Multi-Disciplinary Approach}

Adam Smith was a professor of Moral Philosophy. For a long time, the title of "Political Economy" reflected the understanding that politics could not be separated from economics. This is not the place to trace how the two disciplines got separated. In this brief section, we just want to illustrate how all dimensions of our lives affect each other, and cannot be understood in isolation. To begin with, note that the founding book "The Wealth of Nations" was written because Adam Smith equated wealth with power. Nations with greater wealth would be more powerful, able to win wars, and impose their will on the global theatre. Thus, there is a direct connection between economics and power politics. Findlay and O'Rourke (2009) write that "For much of our period the pattern of trade can only be understood as being the outcome of some military or political equilibrium between contending powers. The dependence of trade on war and peace eventually became so obvious to us that it is reflected in the title of this volume. (Power and Plenty)". 
The institution of Central Banking was created to provide funding for wars, and its initial evolution was governed by this requirement; see Zaman (March 31, 2019). In the nineteenth century, development of banking was driven by the needs of large-scale profitable investments in global colonies of Europe. The economics of the twentieth century cannot be understood without looking at how the two world wars depleted gold stocks at Central Banks, forcing radical changes of the international financial system. See Zaman (May 11, 2018) for more details. Polanyi has shown how politics and society have been shaped by the imperatives of a market economy. For instance, an industrial society requires markets for land and labor. However, putting human lives for sale cheapens lives creates attitudes of indifference to suffering of others, required for functioning of a labor market. Similarly, a market for land reduces our respect for Mother Earth, and enables the rapacious exploitation that is at the root of the looming environmental catastrophe. The point is the economic structures like the market exercise deep influence on political and social institutions, and cannot be studied in isolation.

Building an economics for the 21st Century will require the use of an inter-disciplinary and multi-disciplinary approach. We invite such contributions for future issues of this journal, to enrich our understanding of the economic dimension of our lives.

\subsection{Methodological Communitarianism}

Economic methodology is firmly grounded in "methodological individualism". This means that we can reduce the behavior of groups to the behavior of individuals within that group. By analyzing individual behaviors, and summing them up, we can analyze the behavior of groups. As a simple example, we can compute aggregate demand by summing up the individual demand curves for every individual. The opposite of this is the idea the individual behavior can only be understood within the context of a social community. As an individual, my desires (and demands) are shaped by the community within which I live. The worth of my efforts (labor) and rewards given for this are determined by the social norms of my community. This idea is supported by recent developments in evolutionary biology which show that the forces of natural selection operate at multiple levels. Pro-social behaviors, where individuals act out of group solidarity instead of personal interests, are beneficial for group survival, and are an essential component of human nature. See Wilson (2015) for a book-length argument on the evolutionary emergence of altruism.

In contrast to this, the standard theories of rational behavior are strongly individualistic. They posit the identical behavior for all individuals in all societies at all times. Examination of actual behavior shows radical differences. Amartya Sen noted that only "Rational Fools" would disregard social norms in pursuit of personal pleasure. This is because our lives are interconnected are we are deeply dependent on each other. Polanyi suggest that a better theory for human motivation would be that we seek to maximize our social standing. The markers of social status differ from society to society, and accordingly human motivations also differ.

Changing focus from individuals to communities also permits us to consider social action and the class structure of societies. Historical processes of change are carried out by groups working together for common goals. Individuals are too small to effect history, except when they succeed in inspiring large groups to strive collectively for a shared vision. Methodological individualism of modern economics blinds economists to the powerful effects of community and society, as well as the considerations of class, and conflicts of class interests. The importance of communities, and their neglect by economists, is highlighted by Bowles and Gintis (2012). Similarly, a large number of economic phenomena cannot be understood except 
with reference to class interests and power struggles. For an extended discussion, see Robertson and Leumer (2019).

Apart from politics and class, our lives are enriched or impoverished by communities. Studies of human happiness and welfare show the central importance of social networks, families, friends, and communities. Many authors have noted the increasing breakdown of communities, and the resultant increase in loneliness, unhappiness, and suicides. Parts of the recent declines in life expectancies are the result of this loss of community, invisible to economists because of methodological individualism.

\subsection{Entanglement of Facts and Values}

An essential methodological change required for progress in economics is to move beyond the normative positive dichotomy. The idea that human knowledge can be neatly partitioned into two compartments, one of which is positive (objective facts) while the other is normative (subjective opinions) is at the heart of contemporary methodology. Furthermore, the idea propagated by logical positivism that values or norms cannot be part of science, and the economics is purely positive and free of values is part of textbook economics. To build foundations for a new methodology, we must replace these defective ideas, derived from the failed philosophy of logical positivism.

Hilary Putnam (2002) in the Collapse of the Fact/Value distinction, has shown that while there are statements of facts and statements of value, most of our knowledge consists of a mixture of both. Furthermore, facts and values are entangled so that they cannot be separated. Economics cannot be done without deeply involving values. When we say that rational behavior consists of maximization of lifetime utility, we are providing a normative framework for how human beings should live their lives. This normative framework derives directly from Jeremy Bentham, who thought of himself as the prophet of a new religion, an alternative to and replacement for Christianity. If we believe, like Buddhists, that attachment to worldly goods and pleasures creates suffering, our behavior will be "irrational" by the norms of economists. Studies of human behavior show dramatic differences from rational choice theory (see Zaman and Karacuka, 2012). The failure of economic theories to match actual human behavior has led to widespread consensus that these are normative, and not positive theories; see the introduction to Koehler and Harvey (2008).

Allegiance to positivist methodology forces economists to avoid mention of normative values. At the same time, it is impossible to do economics without a normative framework. The combined force of these conflicting principles forces economists to conceal norms within an apparently objective framework. In Zaman (2012, The normative foundations of scarcity), I have shown that even what is currently taken to be the fundamental defining concept of economics is deeply normative. Along the same lines, Hausman and MacPherson (2006, Economic Analysis, Moral Philosophy, and Public Policy) bring out and highlight normative assumptions hidden within the framework of the economic theories we teach.

There is no possibility of constructing a value free economic theory. Our only option is to explicitly articulate values and formulate economic theories on the basis of openly acknowledged normative frameworks. This opens up an entirely new dimension for research and investigation - the effects of normative ideals on economic policies. We would like to see contributions along these lines in future issues of our journal. 


\section{MULTIPLE FRONTS FOR ACTION}

As we have seen, there are vast areas of research open for out-of-the-box thinking on multidimensional fronts. Among the key areas highlighted by our analysis of methodological weaknesses of current approaches. We highlight some of these areas for action below:

\subsection{Replacing Optimization and Equilibrium}

Mirowski (1992) has described how the enormous prestige of Newtonian Physics led to the conscious effort to mimic mathematical methods of 19th Century Physics in formulating economic theories. The fundamental principles of "Optimization" and "Equilibrium" are at the core of modern textbooks. As countless studies of human decision-making behavior have proven, there is no way to understand it as "optimization"; see Zaman and Karacuka (2012) for a survey of the empirical evidence in this regard. Similarly, Post-Newtonian developments in astrophysics lead to the realization that the universe was born in a big bang and is continuously evolving towards a dynamic heat death. Thus, physics has moved on to dynamical systems with non-equilibrium, evolutionary behaviors. In accordance with these insights, we need to update the methodological foundations of economics in the following two fundamental ways.

\subsubsection{Replace Optimization with Heuristics of Behavior}

There are many reasons why human beings fail to "optimize" in the way that economists believe they do or should. One of the most fundamental reasons for this is "uncertainty" - there is genuine and radical uncertainty about the future. For complicated reasons, economists have accepted a fallacious argument which reduces uncertainty to risk, where all possible future outcomes and their probabilities are known, so that optimizing calculations can be made. For details of this argument and its flaws, see Zaman (2019, Subjective Probability Does Not Exist). However, as the Corona Virus crisis shows, completely unanticipated Black Swan events can and do occur with some regularity. This makes optimization impossible.

Study of actual human behavior shows the widespread use of heuristics as guides to action. Analysis shows that these heuristics work quite well in getting us close to optimal decisions in situations of high uncertainty, with minimal computational cost. A large number of stock market phenomena which cannot be explained by rational choice theory can be easily explained by using models of heuristic decision making. Indeed, as Shiller anticipated in "Irrational Exuberance", the global financial crisis cannot be explained on grounds of rational decisionmaking behavior, but yields to heuristics.

There has been substantial progress in modelling human decision making behaviour, the core of all micro and macro theory. In particular, substantial amount of contemporary research on this topic is collected in Koehler and Harvey (2008). In terms of decision making under uncertainty, heuristics of behavior provide us with required theoretical tools for analysis. These tools have been under intensive by behavioral economists. For informed surveys and popular expositions of the state of the art, see Thaler and Ganser (2015) and Gigerenzer et. al. (2011). The field is sufficiently ripe that applying these heuristics can lead to deep and original insights into many kinds of classical economic problems.

Furthermore, it is now well established that, contrary to orthodox economic thought, social norms are strong determinants of human behaviour. Furthermore, it is possible shape these norms to socially desirable patterns. A convenient entry point to this literature is Bicchieri 
(2016) Norms in the wild: How to diagnose, measure, and change social norms. Using observed heuristics of judgments and decision making, and using and shaping social norms, lead to a radically different theory of human behavior and welfare. Incorporating these theories into our models would radically change the nature of macroeconomics.

\subsubsection{Replace Equilibrium with Dynamic Disequilibrium}

As Keynes noted, "in the long run, we are all dead". Physicists have moved from the equilibria of 19th Century Newtonian astronomy to the study of dynamic systems, which are continuously evolving. To understand dynamical systems, it is essential to study the forces which act upon the system in disequilibrium. The word "disequilibrium" has been replaced by non-equilibrium, since dynamic systems may have no equilibria. There are large numbers of methods for studying non-equilibrium systems, but all of them make heavy use of computing power. Indeed, one of the reasons that economists are committed to equilibria is that it has not been possible to study disequilibria without the computer power that has only recently become available.

Newtonian equilibrium methods have largely been abandoned in modern physics which now uses differential equations to describe dynamical systems. In these systems, disequilibrium dynamics are crucial to understanding the behavior of the system. This progress has been heavily influenced by computers. Even simple three body problems cannot be solved analytically, and require computer-based numerical methods for solutions. Economists have failed to benefit from the revolution in computing power, which enables us to move beyond pen and paper calculations of over-simplified formulae describing the economy. For example, Glötzl et. al. (2019) show how moving from the stationary states of classical physics to modern understanding of dynamic systems would change the mathematics of the Edgeworth Box. Of direct relevance to macroeconomics is Keen (2013) "A monetary Minsky model of the Great Moderation and the Great Recession". This paper creates differential equations which build a strictly monetary macroeconomic model which can generate the monetary as well as the real phenomena manifested by both The Great Recession and The Great Moderation. None of the orthodox monetary models currently in use can produce a long period of apparent stability followed by a crash.

\subsection{Evolutionary Biology}

The original competition and greed paradigm which underlies modern economics came from an evolutionary biology perspective: the idea that competition and survival of the fittest leads to efficiently performing organisms. There has been a quiet revolution in evolutionary biology with respect to this paradigm of competition and survival of the fittest. It turns out that in harsh environments, cooperation is the key to survival. One of the pioneers and leaders of the revolution, Wilson (TheBestSchools, 2019) says that "Even more amazing, human genetic evolution can be understood as a major evolutionary transition. In chimpanzee and most other primate societies, members of a group cooperate to a degree, but are also each other's chief rivals. Even cooperation usually takes the form of small alliances that compete with other alliances within the same group. To the best of our current knowledge, our distant ancestors became adept at suppressing disruptive, self-serving behaviors within their groups, so that succeeding as a group became the primary evolutionary force. We are the primate equivalent of the eusocial insects (ants, wasps, bees, and termites), although most of the proximate mechanisms are of course very different." 
Wilson (2007) provides an easily accessible introduction to a a revolutionary paradigm shift from the survival of the fittest paradigm upon which contemporary economics is founded. For economists, the question of "why people cooperate?" and "why are people altruistic" are puzzles to which large numbers of books and articles are devoted. However, if it was cooperation and prosocial behavior that gave an evolutionary edge to human beings, then selfishness, individualism, and hedonism would need explanation as aberrations from social norms. Evolutionary biology can provide foundations for an alternative theory of human behavior, which is radically different from homo economicus, and substantially more faithful to actual behavior. See Wilson (2015) for an evolutionary biology-based explanation of how altruism is a natural behavior for human beings. One of the reasons that economists have shied away from behavioral economics is that it provides us with a grab-bag of heuristics with no clear explanations. Evolutionary biology provides us with an antidote to arbitrariness. In this connection, Wilson (TheBestSchools, 2019) writes that" the Age of Big Theories is not over. When we step away from the encapsulated world of academic economics, we can see that two Big Theories are alive and well. The first is complex systems theory, which explains the dynamics of complex systems of all sorts. The second is evolutionary theory, which explains the dynamics of living systems of all sorts. Together, they provide a new scientific foundation for economics. ... For example, the lead article for a special issue of the Journal for Economic and Behavior Organization entitled "Evolution as a General Theoretical Framework for Economics and Public Policy" ... and an edited volume entitled Complexity and Evolution: Toward a New Synthesis for Economics, has just been published by MIT Press.

\subsubsection{Four Fundamental Questions}

Wilson (TheBestSchools, 2019) argues that one can organize theories of behavior around four principles first articulated clearly by Tinbergen. He observed that four questions need to be addressed for all products of evolution, concerning their function, mechanism, development, and phylogeny. The function question concerns why the trait exists, compared to many other traits that could exist, often because of the winnowing action of natural selection. The mechanism question concerns how the trait exists in a physical sense. The development question concerns how the trait comes into being during the lifetime of the organism. The phylogeny question concerns how the trait came into being over multiple generations, since evolution is a historical process. The Handbook of Behavioral Economics, and other studies, show a bewildering variety of heuristics which emerge upon study of actual human behavior, instead of axiomatics. These four principles allow us to organize our study of human economic behavior in ways that have been found useful across a broad spectrum, which includes animal behaviors. This provides solid foundations for building an alternative to the currently dominant rational decision maker paradigm.

\subsubsection{Agent Based Modeling}

One immediate objection which arises to introducing complexities of human behavior into economic theory is: "how do we model it?". A model is a simplified representation on which calculations can be done. Limitations on our ability to compute have restricted the complexity of our models. So much so that the DSGE model operates with only one representative agent for the whole economy, creating to a vast range of difficulties for realism. Fortunately, it is now possible to use computer simulations to satisfactorily resolve these difficulties. Agent Based Models allow us to model economies with large numbers of heterogenous agents, with varied and complex rules of behavior, and use computer simulations to calculate the outcomes. Even for very simple events like human motion, it has been found that there are no mathematical 
formulae, but computer simulations can provide excellent models. For a complex system like the economy, it is a fortiori impossible to reduce it a mathematical formula. Agent Based Models have already led to deep insights into emergent properties, where the system as a whole displays patterns which no individual component can. That is, the whole is bigger than the sum of its parts. These emergent properties of complex systems are currently impossible to model using orthodox methodologies of macroeconomic modelling. For an introduction to this area, and further references, see Axelrod (2006).

\subsection{Human Welfare}

In "Models and Reality" (Zaman, 2020, this issue), I have argued that the foundations of economics were re-built on logical positivist foundations in the 1930's. For a detailed discussion of the impact of Logical Positivism on the foundations of economics, see Zaman (2013, Logical Positivism and Islamic Economics). Cooter and Rapaport (1984) described this change as a shift from a conception of economics as based on human welfare, to the new definition by Lionel Robbins based on scarcity. The motivation for this change was furnished by positivist misconceptions that science could not be based on unobservables, and that human welfare was not observable. This change was a double mistake. The first mistake is that science does involve unobservables in an essential way. The second mistake is the human welfare is observable in many different ways. Cooter and Rapaport argue that fulfilling basic needs leads to improved outcomes in health and longevity that are directly observable.

\subsubsection{Centrality of Needs/Wants Distinction}

One of the crucial effects of the scarcity definition was to obliterate the distinction between needs and wants. As modern textbooks write Economics is studies the allocation of limited resources for the satisfaction of unlimited wants. The principle of consumer sovereignty leads to the idea that we cannot question the source of consumer desires, thereby equalizing the desire to listen to Beethoven's Ninth Symphony with the desire of hungry children for food. Whereas old style welfare economics considered the fulfilment of essential needs as being of higher priority, and the desire for luxury as being of low priority, modern economics makes it the job of the economists to try to fulfill all wants and needs, regardless of the source. Section 3.2 of Zaman (2012) explains why this is wrong.

The essential importance of needs/wants is brought out by Islamic teachings, which urge feeding the hungry, and also prohibit fulfillment of idle desires. This allows for a simple solution to the supposedly fundamental problem of "scarcity": simply prioritize needs over wants. Because needs are limited, they can actually be fulfilled. Making sure that all needs are fulfilled will lead to enrichment of lives. The problems of inequality are substantially reduced if all needs are fulfilled, Islam ensures this by giving the poor a right in the wealth of rich. Instead of the impossible task of fulfilling all need and wants, if economists restrict ourselves to feeding the hungry, this would change the fundamental economic problem; see Zaman (2015).

The distinction between needs and wants cannot be made by observing choices; it requires deeper understanding of the roots of human behavior. Zaman (2012) shows that making this distinction changes the fundamental basis of modern economic theory. Needs are satiable, and there is no scarcity in terms of resources available to satisfy basic needs of all human beings on the planet. The central issue becomes one of distribution; scarcity only emerges when we attempt to fulfill needs and wants equally, without prioritizing needs over wants. In terms of 
Macroeconomic policy, the main implication is that inequalities and income distribution are substantially more important than overall economic growth. For example, one should look at growth in the separate income quintiles separately. Doing so for the USA reveals that the vast proportion of the gains from growth have gone to the top $1 \%$ over the past three decades. This has led to the massive inequalities documented by Piketty (2014).

\subsubsection{Easterlin's Paradox}

The importance of directly studying sources of human welfare is brought out by Easterlin's Paradox. This shows that massive amounts of economic growth, and massive differentials in GNP per capita, do not correspond to similar changes in human welfare or "happiness". In cross country studies, countries with very low GNP per capita can have levels of welfare and happiness higher than other countries with ten times more wealth. Similarly, in time series, a ten-fold increase in standards of living does not lead to any increase in overall life-satisfaction or happiness. These findings have dramatic implications for economic policy, since they suggest that we need to pursue de-growth, instead of growth, to improve welfare and happiness. Since these ideas run directly counter to economic theory-based policies for growth being vigorously pursued all over the world, there have been many efforts to rebut and refute Easterlin's Paradox. Easterlin et al. (2010) examine these objections and counter-examples and show how they all confuse the short run and the long run. While increase in GDP leads to a short run increase in happiness, this temporary change does not add to long run happiness.

It is important to understand the reasons for the Easterlin Paradox. The first of these is the needs/wants distinction which is completely ignored in economic theory. While fulfilling needs is genuinely important for happiness, fulfilling wants only leads to an increase in wants, leading to a vicious cycle. The literature on "happiness" points to two explanations. One is the set-point, according to which people quickly get habituated to a particular standard of living as "normal". The second is that people do social comparisons, and happiness results from being above the reference levels of comparison social group. In either case, economic growth creates strong negative externalities for human welfare, a result which has been independently confirmed from many different sources.

One of the viciously wrong and misleading normative principle built into economic theory is the "Coca-Cola Theory of Happiness", according to which consumption of pleasurable goods and services is the secret to a happy life; see Zaman (March 28, 2018). After all, that is why one would seek to maximize utility from consumption over a lifetime. However, countless studies show that sources of long-term human welfare come from social relationships and character, and not from consumption of goods. In particular, greedily consuming at the expense of others is a sure formula for a life-time of unhappiness, because it alienates others, and leads to loss of social relationships. For empirical results, see the 80-year-old long run study of happiness at Harvard, cited in Solan (2017).

There are a large number of areas of active research which emerge from the Human Development revolution pioneered by Mahbubul Haq and Amartya Sen; see Gasper (2011). For example, the capabilities approach puts the development of human capabilities at the center of development. The responsibility of society is to provide all members with sufficient resources so that they can develop their capabilities in whatever direction they choose to. The multidimensional poverty index is an important policy measure which emerges out of this framework, which has already had major impact on policies around the word. For recent 
research along these lines, see Bourguignon and Chakravarty (2019). In future issues of this journal, we would like to encourage publication of research along these lines.

\section{CONCLUSIONS}

Mainstream response to the Global Financial Crisis has been disappointing. As Haldar (2018) notes, the discipline refuses to change. Mainstream economic orthodoxy takes the view that some of our models are wrong, and we can fix problems by building better models. For example, Rodrik (2015) celebrates the variety of models available, and argues that we can always find a model which will work well ${ }^{1}$. However, there are a large number of voices, both insiders and outsiders, who take the view that reform is impossible. For example, evolutionary biologist D. S. Wilson $(2011,2020)$ writes that: "Neoclassical economics provides an outstanding example of the "you can't get there from here" principle in academic cultural evolution. It will never move if we try to change it incrementally. It must be replaced wholesale with a more realistic conception of human nature." Similarly, Varoufakis et. al. (2012) write that: "Sometime in the 1990s, Joseph and I converged on a difficult belief: that in economics, error is not just what happens until one gets it right. It is all one can expect! Serious, Inherent Error is the only thing that can come out of even the most sophisticated economics." This is also the message of Zaman (2020, Models and Reality), that the methodology of economics does not permit the creation of good models, nor the evolution of bad models towards good models in the light of empirical evidence.

In this paper, we have presented seven different schools of thought, all of which are incompatible with mainstream orthodoxy in modern macroeconomics. Similarly, we have presented four different methodological principles, all of which are in conflict with accepted methodological principles currently in use in orthodox modern macro textbooks. Finally, we have provided an action plan of areas where research in directions currently prohibited is likely to yield low hanging fruits. Most of these ideas were developed in the 20th Century, and have played only a marginal role, because they conflict with mainstream views. We must pick up these threads and use them to build foundations for a new economics for the 21 st century. The task of central importance, as the future of humanity on this planet is at stake.

\section{REFERENCES}

Acemoglu, D. (2020) Lecture Notes on Political Economy. https://economics.mit.edu/files/ $\underline{8753}$ (accessed April 17, 2020).

Admati, A. (6 December 2019). There is no Economics without Politics. Evonomics https://evonomics.com/political-economy-blind-spots-and-a-challenge-to-academics/ (accessed April 17, 2020).

Arestis, P. and M. C. Sawyer (2006). A handbook of alternative monetary economics. Edward Elgar Publishing.

Arthur, W. B. (2018). Complexity Economics. Santa Fe Institute webpage, http://tuvalu.santafe. edu/ wbarthur/complexityeconomics.htm (accessed April 17, 2020).

\footnotetext{
${ }^{1}$ Mäki (2018) finds weaknesses and contradictions in all of his major arguments for defense.
} 
Arthur, W. B., S. Durlauf and D. A. Lane (1997). Introduction: Process and Emergence in the Economy http://www2.econ.iastate.edu/tesfatsi/IntroEconomyAsEvolvingCAS.ArthurD urlaufLane1997.pdf (accessed April 17, 2020).

Axelrod, R. (2006). Agent-based modeling as a bridge between disciplines. Handbook of computational economics, 2, 1565-1584.

Bicchieri, C. (2016). Norms in the wild: How to diagnose, measure, and change social norms. Oxford University Press.

Borjas, G. (2016). Labor Economics. $7^{\text {th }}$ Edition, McGraw Hill.

Bourguignon, F. and S. R. Chakravarty (2019). The measurement of multidimensional poverty. In Poverty, Social Exclusion and Stochastic Dominance. Singapore: Springer, 83-107.

Bowles, S. and H. Gintis (2012). Democracy and capitalism: Property, community, and the contradictions of modern social thought. Routledge.

Burnham, P. (2001). Marx, international political economy and globalisation. Capital \& Class, 25(3), 103-112. https://doi.org/10.1177/030981680107500109.

Cooter, R. and P. Rappoport (1984). Were the ordinalists wrong about welfare economics? Journal of Economic literature, 22 (2), 507-530.

Denning, S. (2013). How modern economics is built on the world's dumbest idea. Forbes, http://www.forbes.com/sites/stevedenning/2013/07/22/how-modern-economics-is-builton-the-worlds-dumbest-idea (accessed April 17, 2020).

Dutt A. K. and E. J. Amadeo (1993) A Post-Keynesian Theory of Growth, Interest and Money. In The Dynamics of the Wealth of Nations ed. M. Baranzini and G. C. Harcourt. London: Palgrave Macmillan,

Easterlin, R. A., L. A. McVey, M. Switek, O. Sawangfa and J. S. Zweig (2010). The happinessincome paradox revisited. Proceedings of the National Academy of Sciences, 107 (52), 22463-22468.

Findlay, R. and K. H. O'rourke (2009). Power and plenty: trade, war, and the world economy in the second millennium. Princeton University Press.

Gasper, D. (2011). Pioneering the human development revolution: Analysing the trajectory of Mahbub ul Haq. Journal of Human Development and Capabilities, 12 (3), 433-456.

Gigerenzer, G. E., R. E. Hertwig and T. E. Pachur (2011). Heuristics: The foundations of adaptive behavior. Oxford University Press.

Giovanni, A. (1994). The long twentieth century: Money, power, and the origins of our times. London: Versa. 
Glötzl, E., F. Glötzl and O. Richters (2019). From constrained optimization to constrained dynamics: extending analogies between economics and mechanics. Journal of Economic Interaction and Coordination, 14 (3), 623-642.

Haldar, A. (Dec 14, 2018). Economics: The Discipline that Refuses to Change. The Atlantic, https://www.theatlantic.com/education/archive/2018/12/why-do-econ-classes-barelymention-behavioral-economics/578092/ (accessed April 17, 2020).

Harvey, D. (2017). Marx, capital, and the madness of economic reason. Oxford University Press.

Hausman, D. M. and M. S. MacPherson (2006). Economic Analysis, Moral Philosophy and Public Policy. Cambridge (UK): Cambridge University Press.

Hausmann, R., C. Hidalgo, S. Bustos, M. Coscia, A. Simoes and M. A. Yildirim (2011). The Atlas of Economic Complexity: Mapping Paths to Prosperity. Cambridge: Center for International Development, Harvard University.

Hodgson, G. M. (2002). How economics forgot history: The problem of historical specificity in social science. Routledge.

Kay, J. (2019). Embrace Radical Uncertainty. Blog Post, https://www.johnkay.com/2018/ 04/16/embrace-radical-uncertainty/ (accessed April 17, 2020).

Kay, J. and M. King (2020). Radical Uncertainty: Decision-Making Beyond the Numbers. WW Norton \& Company.

Keen, S. (2013). A monetary Minsky model of the Great Moderation and the Great Recession. Journal of Economic Behavior \& Organization, 86, 221-235.

Koehler, D. J. and N. Harvey (2008). Blackwell handbook of judgment and decision making. John Wiley \& Sons.

Krugman, P. (2009). How did economists get it so wrong? New York Times, 2 (9), 2009.

Lemann, N. (2019). Transaction Man: The Rise of the Deal and the Decline of the American Dream. Farrar, Straus and Giroux.

Mäki, U. (2018). Rights and wrongs of economic modelling: refining Rodrik. Journal of Economic Methodology, 25 (3), 218-236.

Moore, J. (2015). Capitalism in the Web of Life: Ecology and the Accumulation of Capital. London: Verso.

Minsky, H. P. (1986). Stabilizing an unstable economy: The lessons for industry, finance and government. Hyman P. Minsky Archive. 513.

Mirowski, P. (1992). More heat than light. Cambridge Books.

Mitchell, W., L. R. Wray and M. Watts (2019). Macroeconomics, London: Red Globe Press. 
Piketty, T. (2014). Capital in the 21st Century. Harvard University Press.

Putnam, H. (2002). The collapse of the fact/value dichotomy and other essays. Harvard University Press.

Robertson, A. and B. Leumer (Oct 14, 2019). Class Struggle is still the issue, Counterpunch https://www.counterpunch.org/2019/10/14/class-struggle-is-still-the-issue/ (accessed April 17, 2020).

Rodrik, D. (2015). Economics Rules. Why Economics Works, When It Fails, and How to Tell the Difference. Oxford UP.

Romer, P. (2015). Mathiness in the theory of economic growth. American Economic Review, $105(5), 89-93$.

Romer, P. (2016). The Trouble with Macroeconomics. The American Economist, 20, 1-20.

Romer, P. (Feb 10, 2020). What Went Wrong? Blog Post. https://paulromer.net/what-wentwrong/ (accessed February 28, 2020).

Solan, M. (Oct 5, 2017) The secret to happiness? Here's some advice from the longest-running study on happiness. Harvard Medical School , https://www.health.harvard.edu/blog/thesecret-to-happiness-heres-some-advice-from-the-longest-running-study-on-happiness2017100512543 (accessed February 28, 2020).

Solow, R. (2010). Building a science of economics for the real world. House Committee on Science and Technology Subcommittee on Investigations and Oversight, 20. http:// www2.econ.iastate.edu/classes/econ502/tesfatsion/Solow.StateOfMacro.CongressionalT estimony.July2010.pdf (accessed February 28, 2020).

Thaler, R. H. and L. J. Ganser (2015). Misbehaving: The making of behavioral economics. New York: WW Norton.

TheBestSchools (Nov 18, 2019). David Sloan Wilson's Statement: The Neo-Darwinian Revolution Is Far from Complete. https://thebestschools.org/dialogues/evolution-davidsloan-wilson-major-statement/ (accessed February 28, 2020).

Varoufakis, Y., J. Halevi and N. Theocarakis (2012). Modern Political Economics: Making sense of the post-2008 world. Routledge.

Wilson, D. S. (2007). Evolution for everyone: How Darwin's theory can change the way we think about our lives. Delta.

Wilson, D. S. (2011). The Neighborhood Project: Using evolution to improve my city, one block at a time. Little, Brown.

Wilson, D. S. (2015). Does altruism exist? Culture, genes, and the welfare of others. Yale University Press. 
Wilson, D. S. (2020). Failed Economics: Tyranny of Mathematics and Enslaved by the Wrong Theory. Evonomics website, https://evonomics.com/failed-economics-tyranny-ofmathematics-enslaved-wrong-theory/ (accessed February 28, 2020).

Zaman, A. (2010) Scarcity: East and West. Journal of Islamic Economics, Banking and Finance, 6 (1), 87-104.

Zaman, A. and M. Karacuka (2012). The Empirical Evidence Against Neoclassical Utility Theory: A Review of the Literature. International Journal for Pluralism and Economics Education, 3 (4), 366-414.

Zaman, A. (2012). The Normative Foundations of Scarcity. Real-World Economics Review, 61 (26), 22-39.

Zaman, A. (Aug 28, 2013) Summary of the Great Transformation by Polanyi. WEA Pedagogy Blog, shortlink: bit.do/Polanyi (accessed February 28, 2020).

Zaman, A. (2013). Logical Positivism and Islamic Economics. International Journal of Economics, Management and Accounting (IJEMA), 21 (2), 1-18.

Zaman, A. (February 28, 2015). First Fundamental Economic Problem: Feeding the Hungry. Available at SSRN: https://ssrn.com/abstract=2571779 or http://dx.doi.org/10.2139/ssrn .2571779 (accessed February 28, 2020).

Zaman, A. (2016). The Methodology of Polanyi's Great Transformation. Economic Thought, 5 (1), 44-63.

Zaman, A. (March 28, 2018). The Coca Cola Theory of Happiness. Islamic Worldview Blog Post, https://azprojects.wordpress.com/2018/03/28/the-coca-cola-theory-of-happiness/ (accessed February 28, 2020).

Zaman, A. (April 1, 2018). ET1\%: The Blindfolds Created by Economic Theory, WEA Pedagogy Blog, Shortlink: bit.ly/az4et1p (accessed February 28, 2020).

Zaman, A. (May 11, 2018). On the Vital Importance of Understanding International Financial Architecture. WEA Pedagogy Blog Post, https://weapedagogy.wordpress.com/2018/05/ 11/on-the-vital-importance-of-understanding-international-financial-architecture/ (accessed February 28, 2020).

Zaman, A. (March 22, 2018). Method or Madness. WEA Pedagogy Blog Post. https:// weapedagogy.wordpress.com/2018/03/22/method-or-madness/ (accessed February 28, 2020).

Zaman, A. (2019). Islam's Gift: An Economy of Spiritual Development. American Journal of Economics and Sociology, 78 (2), 443-491.

Zaman, A. (March 31, 2019). Origins of Central Banking. WEA Pedagogy Blog Post, https:// weapedagogy.wordpress.com/2019/03/31/origins-of-central-banking/(accessed February $28,2020)$. 
Zaman, A. (December 1, 2019). Subjective Probability Does Not Exist. Available at SSRN: https://ssrn.com/abstract=3496823 or http://dx.doi.org/10.2139/ssrn.3496823 (accessed February 28, 2020).

Zaman, A. (Jan 7, 2020) Policy Implication of Modern Monetary Theory for Pakistan, Talk at State Bank of Pakistan, Karachi. Video \& Writeup available from WEA Pakistan Blog: "1-MMT for Pakistan" Shortlink: bit.ly/mmt4pk1 (accessed February 28, 2020).

Zaman, A. (2020). Models and Reality: How did Models Divorced from Reality become Epistemologically Acceptable? International Econometric Review, this issue. 